\title{
Reported case: Interprofessional approach on the oral rehabilitation of a patient using removable complete dentures
}

\author{
Tatiane Gonçalves Duque ${ }^{1}$, Raquel Virgínia Zanetti ${ }^{1}$, Gisele Ferreira Camargo ${ }^{2}$ and Tânia e Silva Pulicano Lacerda ${ }^{1 *}$ \\ ${ }^{1}$ Dental Prosthesis at São Leopoldo Mandic Graduate School, São Paulo, Brazil \\ ${ }^{2}$ Department of Gerontology, University of Campinas, Brazil
}

\section{Case report}

An elderly woman, 70 years old, Caucasian, reported the following medical history: skin cancer on remission and bipolar disorder, taking anti-depressants and anxiolytics on a daily basis. The patient had already started the process of receiving dental treatment. According to the initial plan, her oral rehabilitation was going to be provided with fixed implants. In order to do so, the professionals did a lower bone graft, but were not successful enough for the execution of the plan. After that, the specialists decided to make a pair of removable complete dentures to be positioned behind the bone. Neither such positioning, the occlusion nor the decreased vertical dimension were adequate, which caused her a lot of pain and difficulty to speak and chew.

There are a lot of plans of action that can be taken when it comes to edentulous patients. They can be treated with conventional complete dentures, an overdenture. When the treatment chosen involves fixed implants it is necessary for the patient to undertake surgical procedures in which the bone is primordial. When the patient does not have enough bones, bone grafts are needed, which is the case here. Fixed implants show better retention. Once the bone was not sufficient, the only line of treatment available is the conventional removable denture. In this specific case, this denture was misplaced and further dental treatment was necessary in order to correct that. This inadequate treatment caused, besides discomfort and pain, further problems in the muscles and stomatognatic system, which made it imperative to align the work of the dentist with the speech therapist. The success of this team work (dentist and speech therapist) promoted not only an improvement in the patients ' physical health, but also had an impact on the patients' psychological condition.

With such challenge in hands, it was decided to first make a bite plate in order to alleviate the pain and correct the position of the prosthesis and muscles. From that moment on, a plan was also developed with a speech therapist who recommended a list of exercises in order to adequate the stomatognathic system as well as speaking, the masticatory, and swallowing functions.

The interprofessional team, then, oriented the patient with exercises that improved intra-oral proprioception, augmented strength and re-taught the positions of the tongue and mandibular movements. The masticatory musculature was worked on and further treatment focusing on the simultaneous bilateral mastication was sought.

In the end, the patient received a new pair of conventional complete dentures, which was supported by the bone, with the correct DVO.
She reported high level of satisfaction with the results, no more pain, speaking and eating better, which even had an effect on her previous psychiatric diagnosis (Figures 1-8).

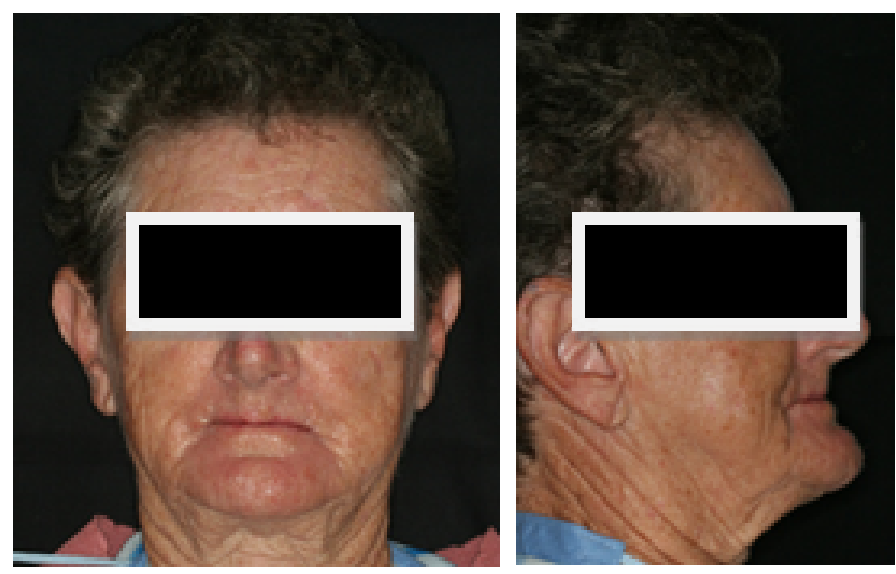

Figure 1. Patient prior to the beginning of the treatment.

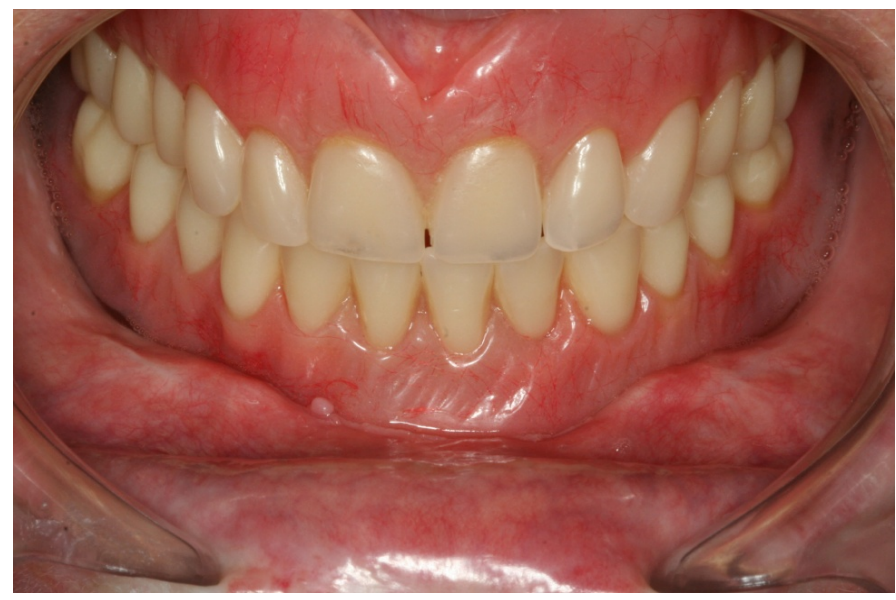

Figure 2. Lower bone graft and complete denture positioned behind the bone.

Correspondence to: Tầnia e Silva Pulicano Lacerda, Professor of Dental Prosthesis at São Leopoldo Mandic Graduate School, São Paulo, Brazil, Email: tanialacerda@ col.odo.br

Received: July 10, 2017; Accepted: August 14, 2017; Published: August 16, 2017 


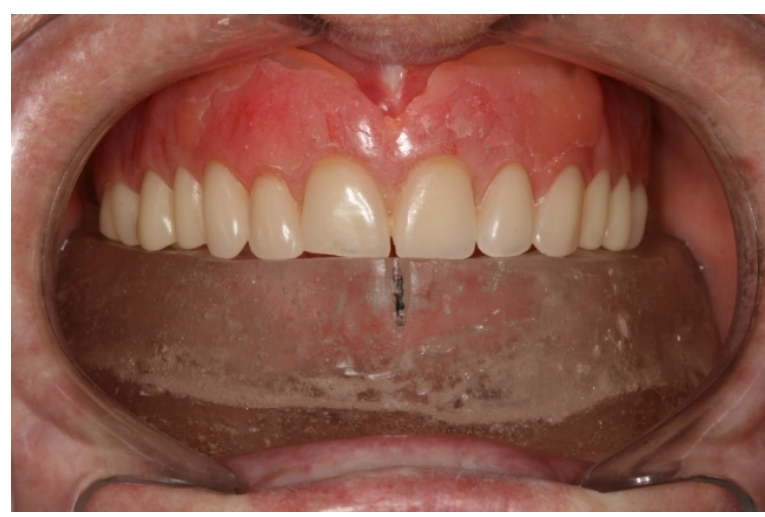

Figure 3. Lower bite plate.

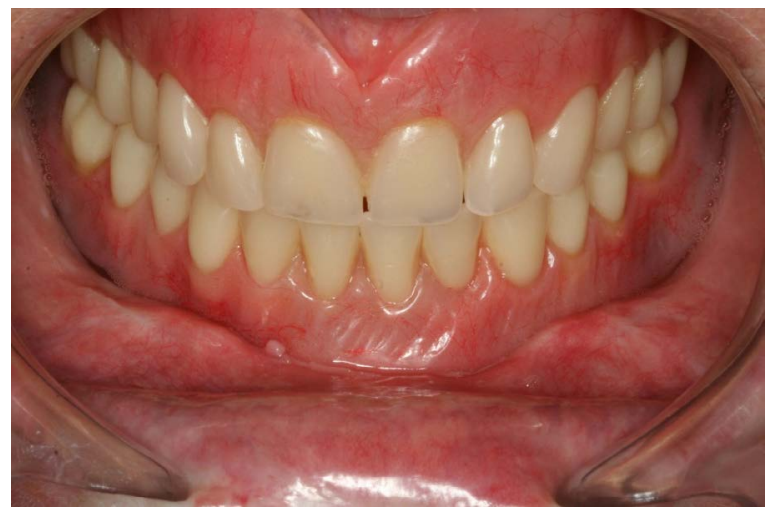

Figure 4. Final Complete Dentures (Upper and Lower).

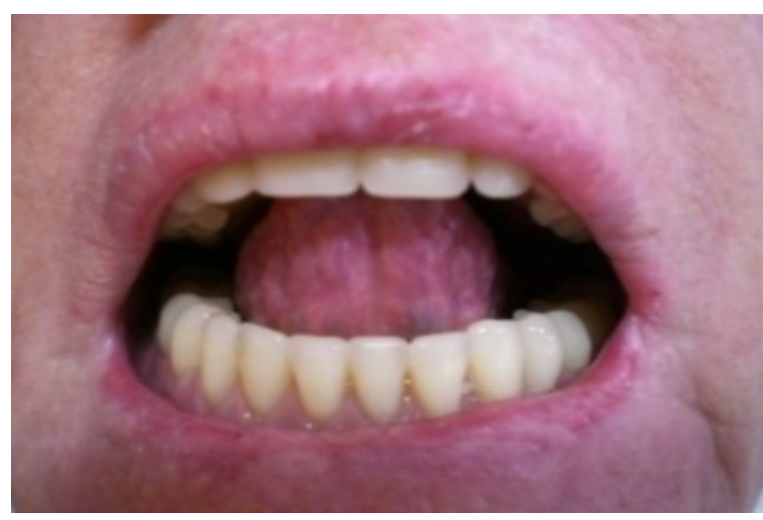

Figure 5. Adequating the mandibular movement.

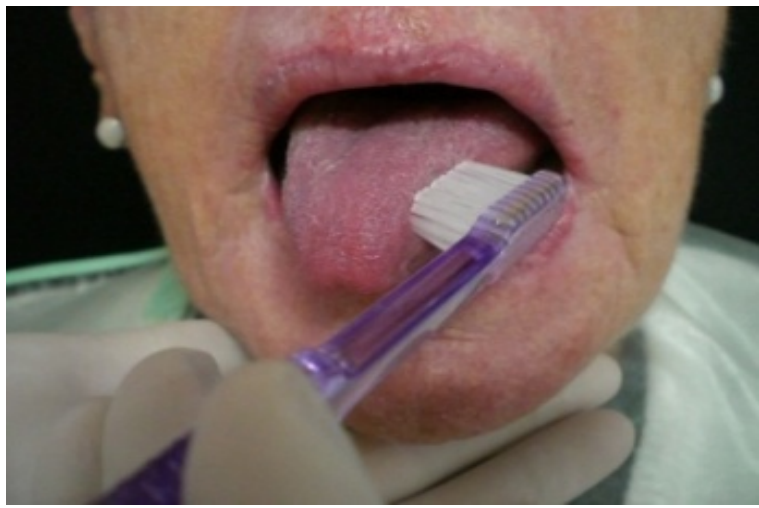

Figure 6. Proprioception and tongue sharpening

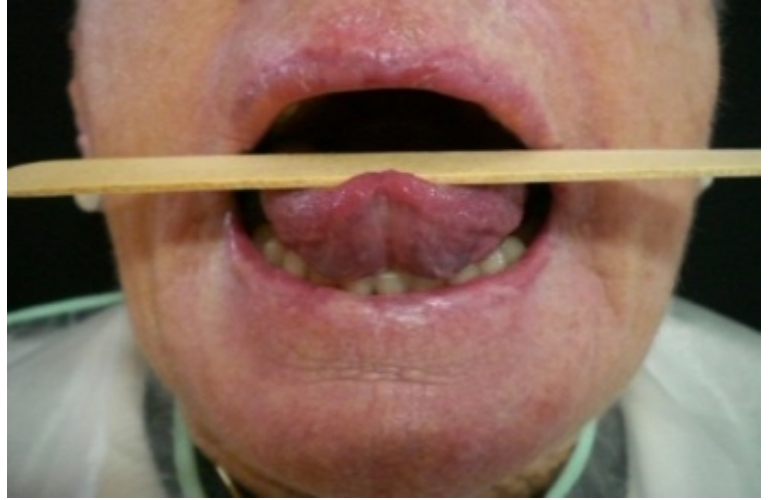

Figure 7. Augmenting the tongue's strength.

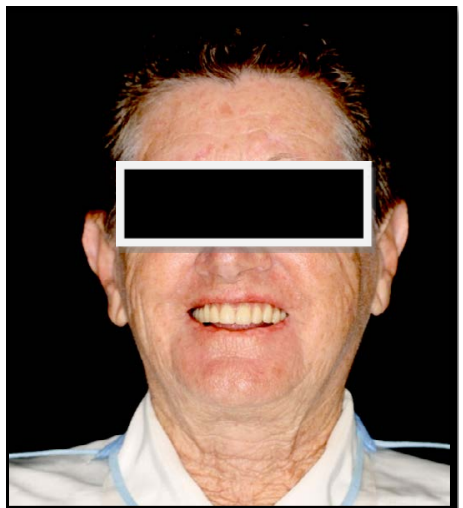

Figure 8. Patient with new removable complete dentures.

\section{References}

1. Bohnenkamp DM, Garcia LT (2007) Phonetics and tongue position to improve mandibular denture retention: a clinical report. J Prosthet Dent 98: 344-347. [Crossref]

2. Camargo GF (2008) Avaliação Fonoaudiológica x autopercepção de saúde bucal em idosos após a instalação de próteses dentárias. Revista da APCD 62: 299-306.

3. Camargo GF, Sousa MLR (2006) A importância da avaliação fonoaudiológica na adaptação dos idosos à prótese dentária. Revista Kairós 9: 303-317.

4. Castro O, e Gomes T (2015) Clonagem terapêutica para Próteses totais e Overdentures. 2a Ed. São Paulo: Santos Editora.

5. Cunha CC (2003) Importância da terapia miofuncional na reabilitação de paciente portador de prótese total. Revista da APCD 57: 101-104.

6. Felício CM, Cunha CC (2005) Relações entre Condições miofuncionais e adaptação de próteses totais. PCL 7: 195-202.

7. Komagamine Y, Kanazawa M, Kaiba Y, Sato Y, Minakuchi S, et al. (2012) Association between self-assessment of complete dentures and oral health-related quality of life. Journal of Oral Rehabilitation 39: 847-857.

8. Sierpinska T, Golebiewska M, Kuc J, Lapuc M (2009) The influence of the occlusa vertical dimension on masticatory muscle activities and hyoid bone position in complete denture wearers. Advances in Medical Sciences 54: 104-108.

9. Silva TR, Canto GL (2014) Integração odontologia-fonoaudiologia: a importância da formação de equipes interdisciplinares. Revista CEFAC 16: 598-603.

Copyright: (C2017 Duque TG. This is an open-access article distributed under the terms of the Creative Commons Attribution License, which permits unrestricted use, distribution, and reproduction in any medium, provided the original author and source are credited. 